\title{
LA FAMILIA MORISCA DE LOS MULEY-FEZ, PRÍNCIPES MERINÍES E INFANTES DE GRANADA
}

\author{
M. ${ }^{a}$ Jesús Rubiera Mata*
}

\section{NúÑeZ MuleY}

En 1566 el morisco granadino Francisco Núñez Muley elevó un Memorial al Presidente de las Reales Audiencia y Chancillería de la Ciudad y Reino de Granada para que se suspendiese la ejecución de la Pragmática que prohibía a los moriscos el uso de sus signos de identidad: lengua, traje, música y otras costumbres profanas. El documento es muy conocido ${ }^{1}$, conservándose algunos resúmenes, entre ellos el de Mármol Carvajal, además del texto original completo ${ }^{2}$. Pero del autor, Francisco Núñez Muley, como dice el profesor Vincent sabemos muy poco. Lo principal proviene de su propio Memorial, donde le vemos desempeñando un puesto relevante entre la aristocracia morisca. Fue paje del arzobispo Talavera:

"Demás desto puedo dezir que yo serví al Santo Arzobispo por tres años y más, por paxe, y fui con él a una véseta que visitó a todas las Alpuxarras [...] Esto me acuerdo dello como si fuese ayer, en el año de quinientos y dos".

Unos años después, en 1513, ya seguramente adulto, fue con una delegación de notables granadinos a entrevistarse con Fernando el Católico: "en dicho año de treze yo fui entre otros caballeros de los naturales deste reino a negocios que convenía con Su Alteza del Rey Católico -que haya gloria- ni había llegado tal cosa a nuestra noticia".

Es él quien hace pregonar la provisión del rey Católico a favor de los moriscos granadinos juntamente con la que hizo el emperador Carlos en el año 1517:

* Universidad de Alicante.

1. Bernard VINCENT, «Estudio preliminar» a la reedición de Los moriscos del Reino de Granada según el Sinodo de Guadix de 1554, Granada, Archivum, 1996, pp. XXVII-LII.

2. Biblioteca Nacional de Madrid, Manuscrito 6176, fols. 325-345. Fue editado por Raymond Foulchè-Delbosc en 1899 y por Kennneth Garrad en 1954. La versión de Foulché ha sido reeditada por B. VINCENT, op. cit., pp. XXV-LII. 
"fuymos ciertas personas, cavalleros, prencipales deste Reino, en compana del Marqués de Mondéjar, para besar las manos de su Real Majestad y darle la norabuena de su venida a reinar en estos sus reinos, y entonces se trataron ciertos negocios ansi en servicio de Su Majestad como en cosas cumplideras a los naturales que habíamos servido y obligado a Su Majestad el servicio ordinario de los veinte y un mil ducados".

Tiene reuniones con los eclesiásticos de más categoría: "y esto lo alcançó por aver un día plática con Don Gaspar de Ávalos, antes que fuese arzobispo" y "Por muchas veces fue platicado esto entre mí y algunos señores inquisidores, y están en esta misma opinión mía, como Vuestra Señoría se puede ynformar dellos".

Otros datos sobre su persona, que Bernard Vincent ha encontrado fuera de lo manifestado en el Memorial, no hacen sino confirmar su elevada posición entre los moriscos ${ }^{3}$ : fue recaudador del impuesto de la farda, cargo en el que le sucedió su hijo Alonso Martínez de Santiago, y ambos recibieron gratificaciones, además de que Francisco Núñez gozaba de un beneficio vinculado a la Alhambra, con otros ocho moriscos, lo que le aseguraba 9.000 maravedíes al año.

Se nos presenta, por tanto, como representante y portavoz de la comunidad morisca granadina, al más alto nivel, como diríamos hoy, y por ello escribe el Memorial en nombre de esta comunidad. Esta elevada situación social, política y económica parece corresponder a un miembro de la familia real nazarí, dado además que el apellido Muley no es otra cosa que el tratamiento que recibían los reyes y príncipes de la familia real granadina: baste recordar el Muley Haçen, Muley Baudili, etc.

Pero hasta ahora no se había encontrado el parentesco real de Francisco Núñèz Muley, porque hay una complicación añadida para buscarle en la compleja parentela nazarí. En el mismo Memorial menciona a unos parientes suyos que parecen tener aún más importancia que él mismo, ya que son los depositarios del documento en el que Carlos V había dejado en suspenso, en 1518, la prohibición del uso y corte del traje morisco: "y está en poder de Don Hernando Muley, mi sobrino, hijo de Don Álvaro de Fez, su padre, ya difunto, que la había traído su agüelo, mi tío, Don Hernando de Fez, difunto" $^{\prime \prime}$ Los nombres de estos parientes parecen indicar un origen marroquí (de Fez) y el "Muley" un linaje real. Hernando Muley, el sobrino de Núñez Muley, aquí mencionado, confirma el origen marroquí de la familia, atribuyéndose un linaje real, en un documento de 1579, señalado por Bernard Vincent": "(soy) de linaje de los rreyes de Fez y Marruecos [...] soy del linaje de los rreyes".

3. Bernard VINCENT, «Et quelques voix de plus: de Francisco Núñez Muley à Fatima Ratal», Sharq al-Andalus. Estudios Mudéjares y Moriscos, 12 (1995), p. 136.

4. «La familia morisca», Minorías y marginados en la España del siglo XVI, Granada, 1987, p. 22. 


\section{FERNANDO DE FEZ}

Los importantísimos documentos de las nóminas de los conversos granadinos de 1499-1500, publicados por Miguel Ángel Ladero Quesada ${ }^{5}$, nos van a dar la clave de la identidad de los Muley-Fez. En el registro 296 y $297^{6}$ se dice:

"Don Fernando de Fez, que se llamaba [en blanco], de hedad LV años. Bive fuera de la çibdad en un carmen suyo.

Su muger, que se llamó doña Ysabel que antes se desía [en blanco]. Es hija del rey Muley Buliaçen de L años".

Hernando o Fernando de Fez, el tío de Núñez Muley, estaba casado con una hija del sultán nazarí Abū-l-Hasan 'Alī (Muley Haçén o Buliaçen) y era, por tanto, cuñado de Boabdil. Como ya estudiamos hace tiempo, el vínculo cognaticio funcionaba dinásticamente entre los nazaríes desde el siglo $\mathrm{XIV}^{7}$, por lo que las mujeres nazaríes transmitían los derechos al trono. Así Álvaro de Fez y su hijo don Hernando de Fez, nieto y bisnieto, respectivamente, de Muley Hazén, eran príncipes nazaries, es decir infantes de Granada.

Otro documento publicado por Ladero, esta vez la relación de Mercedes reales concedidas a nuevos cristianos para compensar su conversión y evitar los prejuicios económicos que pudiera causarles" ${ }^{8}$, Legajo 59, dice: "20.000 de por vida a Don Fernando de Fez, antes Abulhacen Almutaguaguil, 22 de Noviembre $1500^{\prime \prime}$.

Con lo que sabemos hasta ahora, estas breves líneas no tienen desperdicio. En primer lugar es una alta merced, como corresponde a un miembro de la familia real, pero ya hemos visto que era yerno de Muley Haçén. Y se llamaba Almutaguáguil, que debe ser Al-Mutawakkil, que no es un nombre sino un laqab o título califal. Los sultanes nazaríes nunca habian tomado sobrenombres califales, pero quienes sí lo habían hecho eran los meriníes de $\mathrm{Fez}^{9}$, lugar que este personaje había incorporado a su apellido, y su presencia en Granada le descarta como miembro de la familia reinante de los Watțasies.

En el año 1465, cuando Fernando de Fez tenía diecisiete años, una revolución en Fez acabó con el último amir al-mu'minīn meriní, el sultán. 'Abd al-

\footnotetext{
5. Utilizamos la última edición, Granada después de la conquista. Repobladores y mudéjares, Granada, 1993, pp. 615-649.

6. Ibidem, p. 649.

7. M. Jesús RubierA, «El vínculo cognático en al-Andalus», Andalucía Medieval. Actas I Congreso Historia de Andalucía. Diciembre 1976, vol. I, Córdoba, 1978, pp. 121-124.

8. M.A. LADERO, op. cit., pp. 593-603.

9. Maya ShatzMiller, «Marīnides», E.I., Leiden, VI, pp. 556-559.
} 
Haqq ibn Abī Sa'īd y con su dinastía ${ }^{10}$. Aunque no había ninguna noticia, hasta ahora, pudo ser que parte de su familia lograse huir y refugiarse en Granada, donde en estas fechas reinaba Muley Haçén (1464-1482), que casó al príncipe huido con una de sus hijas, y éste usaba el título califal como sultán meriní en el exilio.

Hernando de Fez, el rey exilado "Al-Mutawakkil", es testigo de la "probanza" de 1503 de los Infantes de Granada, don Fernando y Don Juan, hijos de Muley Hazén y de la cautiva cristiana Turayya, documento estudiado por López de $\mathrm{Coca}^{11}$. En él Fernando de Fez se llama Fernando Abdilhaque de Fez, lo que confirma su linaje meriní ya que el último sultán de esta dinastía, posiblemente su padre, se llamaba 'Abd al-Haqq.

En este documento también se dice que antes era Muley Seyen, nombre que aún aparece en su testamento, otorgado el 3 de julio de $1537^{12}$ y que corresponde a Zayyān, nombre frecuente entre los últimos meriníes como kunya (Abū Zayyān) que acompañaba normalmente al nombre de Muhammad. Posiblemente haya algún error del copista en el documento de las Mercedes, donde su kunya es Abulhaçan, lo que correspondería al nombre de 'Alī.

Pero aún podemos encontrar más datos del nombre musulmán de Fernando de Fez, pues aparece en otros documentos de antes de la conversión forzosa de 1500 . Se trata de las cartas de poder de representación otorgadas en 1492 por "Abd Allah al-Qabšanī, al "ynfante Abi Zayen, hijo del viejo Abdulhac Alavdihaquir", publicadas por Rafael G. Peinado Santaella ${ }^{13}$. Era en efecto Abū Zayyān, hijo del último sultán meriní, 'Abd al-Haqq, y su nombre completo sería Aba Zayyãn Ibn 'Abd al-Haqq ibn Abi Sa'îd, con el título califal de Al-Mutawakkil. Su nombre podría ser Muhammad como correspondería a su kunya, o tal vez 'Abd al-Haqq, que podría ser la lectura del extraño Alavdihaquir.

Según su propio testimonio ${ }^{14}$ Abū Zayyān Ibn ‘Abd al-Haqq acompañó a Boabdil en el exilio, pero luego volvió a Granada. Es evidente que comprobó que ser descendiente del último sultán meriní le impedía vivir en Ma-

10. Mercedes GARCIA ARENAL, "The revolution of Fãs in 869/1465 and the death of Sultan 'Abd al-Haqq al-Marini», Bulletin of the School of Oriental and African Studies, University of London, XLI, 1978, pp. 43-66.

11. J.E. LOPEZ DE COCA CASTAÑER, «Granada en el siglo XV: las postrimerías nazaríes a la luz de la probanza de los Infantes Don Fernando y Don Juan», Andalucia entre oriente y occidente (1236-1492), Actas del V Coloquio Internacional de Historia Medieval de Andalucía, Córdoba, 1988 , pp. 599-641.

12. Este dato nos ha sido suministrado amablemente por Amalia García Pedraza.

13. «Los Banū al-Qabšanī: un linaje de la aristocracia nazarí», Historia, Instituciones, Documentos, Universidad de Sevilla, 20 (1993), pp. 313-353.

14. J.E. LOPEZ DE COCA, op. cit., p. 611. 
rruecos, donde reinaba la dinastía que había derrocado y hecho matar a su padre. $Y$ este hecho le convierte en una figura excepcional: es el único miembro de la antigua corte nazarí que no puede emigrar y ha de quedarse en la situación que los vencedores decidan para los moriscos y, por ello, se ve indudablemente obligado a bautizarse. Los Reyes Católicos parecen reconocer su estatuto real: posiblemente sean los padrinos de su bautismo y el de su mujer, la hija de Muley Haçen, ya que reciben el nombre de Fernando e Isabel, y le otorgan una cuantiosa pensión, sólo inferior a aquellos que fueron "colaboracionistas" por propia voluntad, como don Pedro de Granada ${ }^{15}$. Fernando de Fez fue también beneficiario de la farda $a^{16}$ y posiblemente recibió otros beneficios reales ${ }^{17}$.

Posiblemente tuvo una preeminencia moral y protocolaria entre la comunidad morisca granadina, por encima de otros nobles nazaríes, cuyos vínculos con la familia real eran menores y no sumaban la genealogía meriní. Seguramente presidiría la delegación de los "caballeros principales" de los que habla su sobrino Núñez Muley, que se entrevistaron con Fernando el Católico y con Carlos V, pues como hemos visto fue él el depositario del documento real. También aparece como testigo principal en diversas "probanzas", a través de las cuales podemos saber algunos datos más sobre su persona. Así, en la probanza de sus cuñados, hijos de Muley Haçén, los infantes don Fernando y don Juan, estudiada por López de Coca, afirma "que fue criado y vivió con el rey Muley Bulihaçen". También, a través de este documento, sabemos que don Fernando era aljamiado -hablaba español- y que vivía en la parroquia de Santa María de la O, situada en plena madīna granadina, al oeste de la Madrasa ${ }^{18}$. En los habices de 1505 se confirma su presencia en esta parroquia, como arrendador de una almazara ${ }^{19}$, lo que no es incompatible con que tuviera un carmen fuera de la ciudad.

15. Manuel Espinar Moreno y Juan Grima CeRVANTES, «Un personaje almeriense en las crónicas musulmanas y cristianas. El infante Cidi Yahya Alnayar (1435?-1506)», Boletín del Intituto de Estudios Almerienses, 7 (1987), pp. 57-83, y «Testamento y muerte de D. Pedro de Granada», Mayurqqa, 22 (1989), pp. 39-254.

16. Bernard VINCENT, «Las rentas particulares del reino de Granada en el siglo XVI: fardas, habices, hagüela», Andalucía en la Edad Moderna. Economía y sociedad, Granada, 1985, p. 185.

17. Enrique SORIA MESA, «De la conquista a la asimilación. La integración de la aristocracia nazarí en la oligarquía granadina», Areas, Murcia, 14 (1992), p. 55, nota 37 cita que Don Hernando Abdelhaque de Fez, vecino de Granada, que ahora sabemos que es Fernando de Fez Muley, el 12 de marzo de 1528 da poder para cobrar los seis mil maravedíes que por merced real cobra cada tres años.

18. Luis SECO DE LuCENA, La granada Nazari del siglo XV, Granada, 1975, pp. 61 y 67.

19. M. ${ }^{a}$ del Carmen Villandeva Rico, Habices de las mezquitas de la ciudad de Granada y sus alquerías, Madrid, 1961, p. 39. 
En otra probanza ${ }^{20}$ confiesa que era sobrino de la mujer de Muhammad el Cojo, un nuevo vínculo agnaticio con los nazaríes. Estas comparecencias como testigo posiblemente constituian un ingreso en sus arcas ${ }^{21}$.

Habrá seguramente más datos sobre su persona en la documentación granadina, puesto que hasta ahora sólo hemos utilizado las ya publicadas.

\section{Los otros Muley Fez}

Los privilegios de Fernando de Fez fueron compartidos por otros miembros de su familia, lo que explica la posición de su sobrino Núñez Muley. Aún no sabemos quién era el padre de éste. Tal vez era hijo de una hermana de Fernando de Fez, ya que no parece utilizar el "Fez" como apellido como sus parientes. Hay un "Muley, cuñado del ynfante Muley, llamose don Fernando" en las nóminas de los bautizos de los granadinos ${ }^{22}$, tal vez su padre, con lo que tendríamos otro Fernando Muley, distinto a Abū Zayyān Al-Mutawakkil, que no utiliza el "Fez", por ser cognado de la familia. Pero hay más bautizados con el apellido Muley en las nóminas de bautizados en $1500^{23}$.

No hay datos, por ahora, del hijo de Fernando de Fez, Álvaro de Fez, pero sí de su nieto y homónimo, Fernando, que parece haber heredado la posición política de su abuelo en cuanto a la representatividad de la comunidad morisca granadina. Aparece con el nombre de Hernando de Mendoza de Fez Muley ${ }^{24}$, por lo que suponemos que el Mendoza es el apellido de su madre, y estuvo casado con Florencia Enríquez Çaybona ${ }^{25}$. El apellido musulmán de su mujer nos hace sospechar que los Muley-Fez no practicaban matrimonios exogámicos -el Mendoza de su madre puede ser morisco ya que es un apellido frecuente entre los granadinos convertidos- frente a otros miembros de la aristocracia morisca granadina que emparentaban con las grandes familias cristianas ${ }^{26}$, lo que es coherente con el papel que desempeñan los Muley-Fez como auténticos representantes de la comunidad morisca

20. R.G. PEINADO SANTAELla, op. cit., p. 321.

21. Al menos cobró por su función de apoderado de al-Qabšanī, vid. ibidem, p. 347.

22. M.A. LADERO, op. cit., p. 646, registro 6167.

23. Ibidem, n. 5855 a 5860 , p. 647. Esperamos encarecidamente que el profesor Ladero publique el resto de las nóminas.

24. Camilo ÁlVAREz DE MORAles, «Lorenzo el Chapiz y el "negocio general" de 1559», Qurtuba. Estudios andalusies, Córdoba, 1 (1996), p. 30.

25. Dato suministrado por Amalia García Pedraza, según un documento de venta del 4 de marzo de 1561.

26. E. SORIA MESA, op. cit., p. 53. 
frente a otros miembros de la aristocracia granadina, los que pueden tildarse de auténticos "colaboracionistas" 27 .

Como su tío Núñez Muley, Fernando de Fez Muley actúa como representante de los moriscos en el "negocio general" que afectaba a los "nuevamente convertidos de este reino" y que era, según Camilo Álvarez de Morales que ha descubierto tan importante asunto ${ }^{28}$, el intento de lograr que el Santo Oficio dejase cierta tranquilidad a los moriscos a cambio de un tributo. Para ello había viajado en $\mathbf{1 5 5 6}$ a las Alpujarras, gastándose quinientos ducados, y fue preso de la Inquisición durante diez meses. Más tarde se trasladaría con el mismo fin a Málaga y Vélez Málaga. Si el "negocio general" quería dar a la comunidad morisca cierta tranquilidad en la práctica de costumbres musulmanas, podemos pensar que era algo muy semejante a lo que intentó su tío en 1567 con su Memorial, pues no cabe pensar que la Inquisición transigiese en otras cosas que no fuesen lengua, traje y zambras, que en sí no tenían nada de heterodoxo teológicamente.

Fernando de Fez Muley tuvo muy poco éxito en su misión, pues algunos moriscos como el Chapiz se negaron a pagar su parte en los gastos y las autoridades cristianas hicieron oídos sordos 29 . Aún más, además de sufrir prisiones por la Inquisición, fue expulsado de Granada y sus bienes confiscados, juntamente con su hermano Andrés. Solicitó el regreso y la restitución de sus bienes, alegando su linaje real y que tenía catorce hijas y nietas a su cargo, todas viudas ${ }^{30}$, cosa que consiguió, porque figura entre los moriscos que se quedan en Granada después de la expulsión de 1570 ${ }^{31}$. Posiblemente por estas dificultades actuó como portavoz de la comunidad morisca su tío Núñez Muley en lugar suyo como genealógicamente le correspondía.

Todavía en el año 1587 nos encontramos a un Hernando Muley acompañando a Alonso del Castillo para tomar posesión en Madrid como traductor real $^{32}$. Es posible que sea la misma persona, ya que los Muley parecen longevos, y querría una vez más hacer su papel de máximo representante de los moriscos o, tal vez, sea un hijo suyo ${ }^{33}$.

27. Bernard VINCENI; «Et quelques voix de plus...», pp. 131-161.

28. Ver nota 24 , pp. 27-28.

29. Ibidem.

30. Bernard VINCENT, «La familia morisca...», p. 22.

31. Bernard VINCENT, «Los moriscos que permanecieron en el Reino de Granada después de la expulsión de 1570», Andalucía en la Edad Moderna. Economía y sociedad, Granada, 1985, pp. $267-286$.

32. Darío Cabanelas Rodriguez, El morisco granadino Alonso del Castillo, Granada, 1991 (2." ed.), P. 223.

33. Unos Hernando Muley y Andrés Muley organizan un compló en Sevilla en 1580. Antonio DOMínGUEZ ORTIZ, «Desventuras de dos moriscos granadinos», Homenaje al prof. Jacinto Bosch Vila, Granada, 1991, pp. 89-94. Este Hernando Muley, que terminó en galeras, es su hijo puesto que lleva el apellido de su esposa, Enríquez. 


\section{LA RESISTENCIA INTELECTUAL}

Es evidente que quedan muchas lagunas en la historia de los $\mathrm{Fez}$ Muley, pero me ha parecido importante adelantar la identificación genealógica de la familia como príncipes meriníes, lo que explica su estatuto privilegiado dentro de la aristocracia morisca y el papel que desempeñaron en la Granada del siglo XVI.

Como príncipes meriníes eran los únicos miembros de la familia real nazarí que no podían emigrar a Marruecos, aunque hicieron algún intento. En Granada ocuparon el espacio vacío de la familia nazarí, moralmente, ejerciendo una función que podríamos llamar dinástica, ya que frente a otros parientes no habían renunciado a su propia identidad $-\mathrm{y}$ posiblemente a su religión-, e intentaron que persistiese una comunidad morisca con sus señas de identidad. Fracasaron, pero frente a Aben Umaya, otro morisco de sangre real, no parece que participasen en la rebelión de las Alpujarras. Cabe preguntarse si en cambio no fue en su círculo donde se tejió esa otra resistencia, la intelectual, que se plasmó en los Libros Plúmbeos, donde la arabicidad y el Islam se presentaban como los pilares históricos de Granada, en un intento para evitar la expulsión definitiva e incluso "islamizar" el cristianismo ${ }^{34}$.

Recordemos lo que escribiera Luis de Mármol Carvajal al arzobispo don Pedro de Castro, a propósito del origen de los Libros Plúmbeos:

"Y mande $V^{a}$ Señoria que el dicho licenciado castillo a quien oyó decir, cuatro o seis años antes del alçamiento de los moriscos, que cuando derribasen aquella torre se hallaría allí un gran pronóstico, porque él ha dicho a mí que un morisco antiguo llamado el $\mathrm{Merini}^{35}$, que murió el primer año del rebelió, se lo dixo, y no lo debió decir a sólo él, y parece que ya era negocio entre ellos, porque el meriní presumía de muy leído y tenía muchos papeles árabes" ${ }^{\prime \prime 3}$.

\section{RESUMEN}

La familia morisca de los Muley-Fez desempeñan un importante papel en la Granada del siglo XVI, siendo especialmente conocido Francisco Núñez Muley. Hasta ahora no se sabía la razón genealógica de esta importante posición. En este artículo se prueba que Hernando o Fernando de Fez

34. Mikel de EPALZA, «Le milieu hispano-moresque de l'Évangile islamisant de Barnabé (XVIeXVIIe s.)», Islamochristiana, 8 (1982), pp. 159-183; Luis F. BERNABÉ PONS, El Evangelio de San Bernabé. Un evangelio islámico español, Alicante, 1995.

35. La cursiva es mía.

36. Darío CabAnelas, op. cit., p. 253. 
Muley era hijo del último sultán meriní de Marruecos, asesinado en 1465. Refugiado en la corte granadina, el príncipe meriní se casó con una de las hijas del sultán nazarí Abū-l-Hasan (Muley Haçen), con lo que el linaje de los Muley-Fez tenía un doble vínculo real como sucesores de la dinastía meriní y cognados de los nazaríes.

\section{ABSTRACT}

The Moorish family of the Muley-Fez performs an important role in the Grenada of the 16th century, being especially known Francisco Nuñez Muley. The genealogical reason of this important position has not been known until now. In this article we state that Hernando or Fernando de Fez Muley was a son of the last meriní sultan of Morocco, murdered in 1465 . He took refuge in the court in Grenada, the meriní prince got married to one of the daughters of the nazarí sultan Abu-l-Hasan (Muley Haçen), so the lineage of the Muley-Fez had a double real link as successors of the merini dynasty and "cognates" of the nazaríes. 